\title{
A Different Three-Port DC/DC Converter for Standalone PV System
}

\author{
Nimrod Vázquez, ${ }^{1,2}$ Carlos Manuel Sanchez, ${ }^{3}$ Claudia Hernández, ${ }^{1}$ Eslí Vázquez, \\ Luz del Carmen García, ${ }^{1}$ and Jaime Arau ${ }^{5}$ \\ ${ }^{1}$ Electronics Engineering Department, Technological Institute of Celaya, 38010 Celaya, GTO, Mexico \\ ${ }^{2}$ Applied Mathematics Division, Potosino Institute of Scientific and Technological Research, 78216 San Luis Potosi, SLP, Mexico \\ ${ }^{3}$ Electrical Engineering Department, Michoacana University, 58030 Morelia, MICH, Mexico \\ ${ }^{4}$ Engineering Faculty, Veracruz University, 94294 Boca del Rio, VER, Mexico \\ ${ }^{5}$ Electronics Engineering Department, Cenidet, 62490 Cuernavaca, MOR, Mexico
}

Correspondence should be addressed to Nimrod Vázquez; n.vazquez@ieee.org

Received 29 November 2013; Revised 17 January 2014; Accepted 17 January 2014; Published 2 March 2014

Academic Editor: Ismail H. Altas

Copyright (C) 2014 Nimrod Vázquez et al. This is an open access article distributed under the Creative Commons Attribution License, which permits unrestricted use, distribution, and reproduction in any medium, provided the original work is properly cited.

\begin{abstract}
A three-port converter suitable for standalone applications is proposed in this paper. Each port is used for specific input or output, and its functions depend on the port; they are the renewable source, the battery set, and the output port. This proposed converter is considered for standalone operation, but it is not limited to it. Not only the system is able to deliver energy independently from each input source or in a mixed way for the output, but also the battery system may be charged from the renewable source just in case it is required. The battery port is only used when it is required; this allows increasing battery lifetime. Another important feature is that, in case of a renewable source failure, the energy is automatically demanded from the battery set, like an uninterruptible power supply. The system is able to track the maximum power of the renewable source when it is required. Operation, analysis, simulation, and experimental results are described in detail.
\end{abstract}

\section{Introduction}

Since fossil fuels are depleting, it is important to study some different choices in order to be able to supply the required worldwide energy. Renewable energy is taken into account more seriously nowadays. There exist applications of renewable energy which employ hundreds of MW (high power) and there are also those which use hundreds of W (low power). Applications may be distinguished depending on if they are connected to the grid or not, also known as cogeneration or standalone systems, respectively; the last one is especially employed in remote places, where utility is not available. The proposed converter can be used in remote places where the utility is not available, but also as satellite power supply, electric vehicles, and other applications that consider a battery set as an input.
Photovoltaic panel arrays should be the main source of energy in standalone systems. Since there is no utility line, which implies that an effective use of energy is very important, a battery set is needed in order to be able to supply energy in case the renewable source is an irregular way; leaving aside the power management a power converter stage is needed in order to assure output power. DC/DC converters suitable for standalone applications can be classified into multistage or integrated-stage topologies (Figure 1).

Multistage converters [1-12] are able to control each input independently but share a single output, with the aid of a common DC bus voltage, as shown in Figure 1(a); for standalone operation this configuration implies a bidirectional converter for the battery port; as a consequence, operation becomes complex because both sources should be able not only to deliver energy but also to manage the battery charging/discharging. In these schemes the energy to charge 


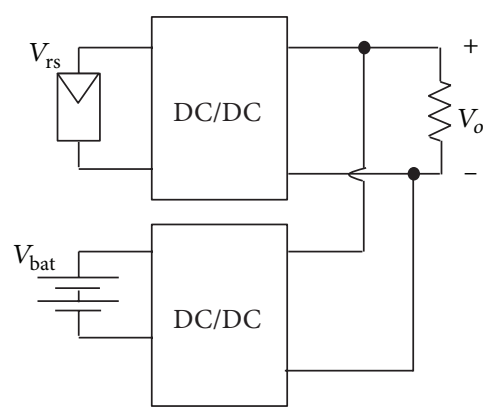

(a)

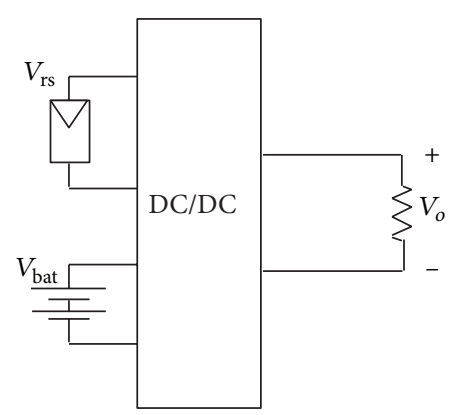

(b)

FIGURE 1: Standalone systems: (a) multistage, (b) integrated stage.

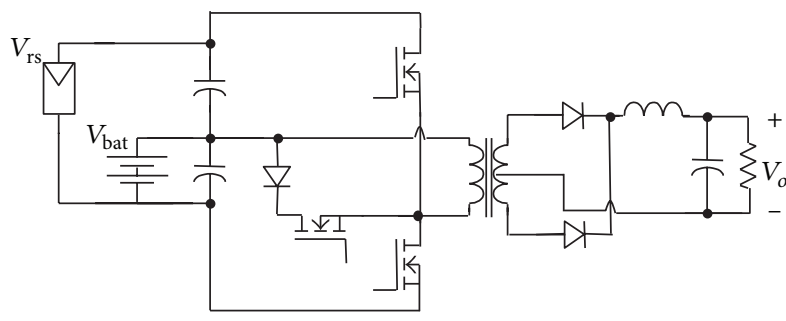

Figure 2: Three-port converter proposed in [8].

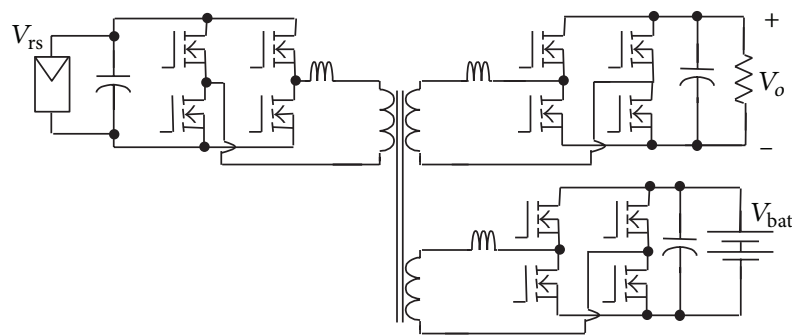

FIgURE 3: Three-port converter proposed in [9].

the battery is processed twice, the first one to deliver energy to the common bus and then to charge the battery.

Integrated-stage converters [1-11] should be able to demand current from both inputs in the easiest way (Figure 1(b)). Some of them do not include bidirectional converters, and the battery charging is not possible unless another converter is considered $[5,6]$. There are three-port converters, suggested in the literature, that consider a battery set [7-12].

Proposal in [8] is shown in Figure 2; unfortunately this configuration uses the battery set during all the different modes of operation, which reduces its lifetime. Figure 3 shows a converter based on full-bridge inverter and a transformer [9]; mainly the disadvantage of this topology is the semiconductors count. There are other schemes for threeport converter [10-12], but these are very similar to those two mentioned previously.

A different three-port converter topology is proposed in this paper; not only semiconductors count is reduced and the battery set is used when it is only required to do so, but also

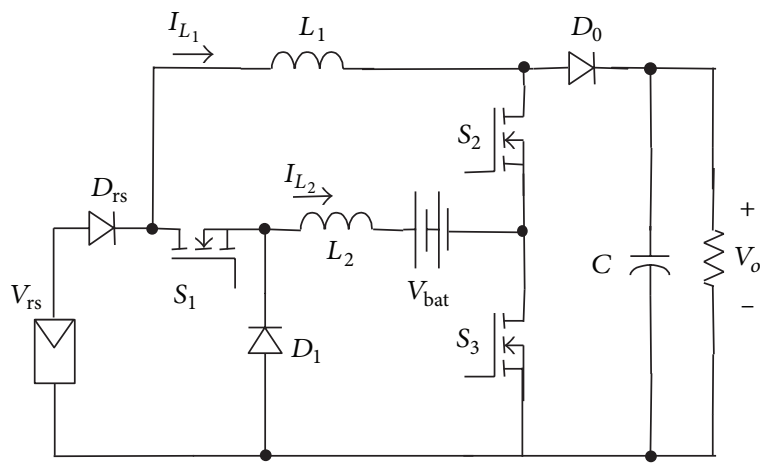

Figure 4: Proposed converter.

the power flow is controlled easily. The system accepts two input voltages and the energy may be supplied from both inputs simultaneously or independently, depending on the availability of the input voltage source. One of these inputs is the battery set, which may be charged from the renewable source if it is necessary. Battery set is involved only when the system requires it, so that its lifetime increases.

Information is organized in this paper as follows: threeport converter proposal is discussed in Section 2, which includes system operation and analysis. Section 3 is addressed for control operation of the proposed system. Experimental results are discussed in Section 4, and some final conclusions are given.

\section{Proposed Three-Port Converter}

Three-port converter proposal, shown in Figure 4, is suitable for renewable energy application, especially for standalone applications, where a battery set and power flow management are required. This last feature can be carried out easily in the proposed converter.

The system is composed of three switches, three diodes, two inductors, and one capacitor, as shown in Figure 4. Each switch determines the operation of the system; this allows an easy and good power management.

For standalone systems energy is mainly provided from renewable source, which depends on weather conditions. Then the battery set is considered in order to guarantee 


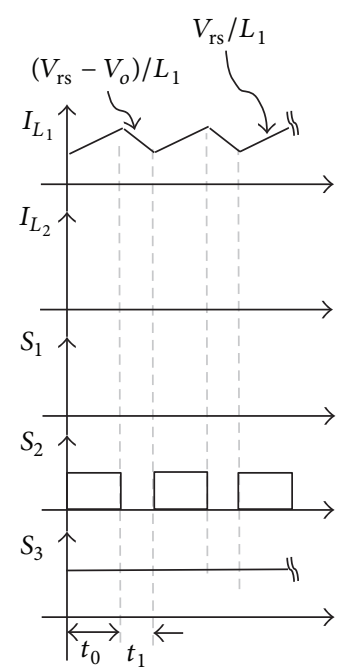

(a) Waveforms

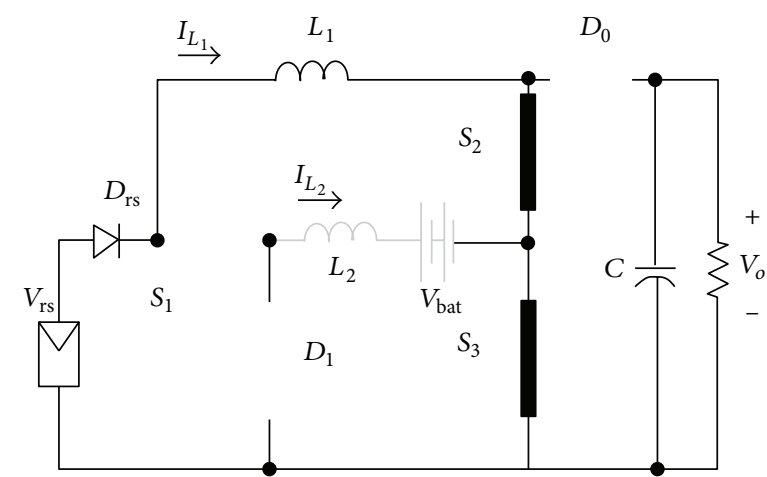

(b) Subcircuit for $t_{0}$

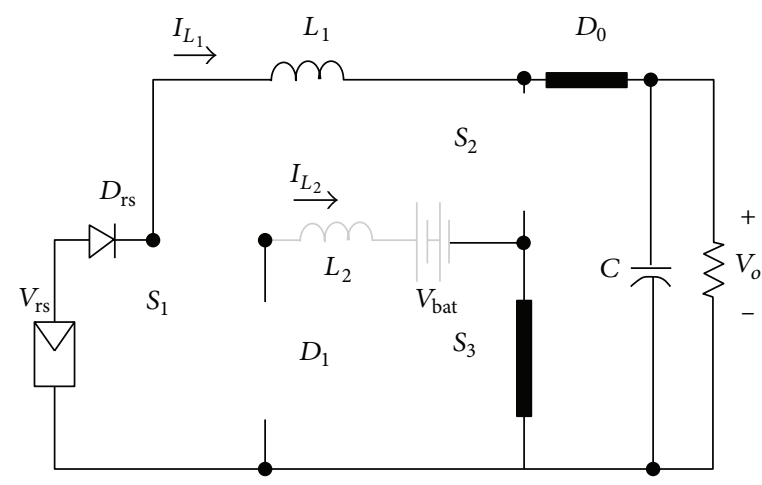

(c) Subcircuit for $t_{1}$

FIGURE 5: Waveforms and subcircuits when the energy is obtained from the renewable source (mode 1, no charging).

energy supply. Since energy consumption is restricted to a maximum limit, this has to be optimized.

When considering a photovoltaic system and a specific load connected in the standalone operation, there exist many different possibilities; these scenarios must be taken into account in the power converter in order to provide a constant and regulated output voltage no matter weather conditions. Each scenario considers different stages depending on the required functions; next are described the operating modes of the system.

2.1. Mode 1: Delivered Energy from the Renewable Source. This mode happens when there is enough energy to feed the load; however the battery set may be charged or not depending on its conditions. Particularly for this operation mode, the switch $S_{3}$ is turned on all the time (Figures 5 and 6). Then $S_{2}$ is used to regulate the output voltage, and $S_{1}$ is used to charge the battery set. The two switches are easily controlled independently, because these are uncoupled.

In this mode the renewable source voltage is higher than the battery set voltage, and then the diode in antiparallel of $S_{1}$ is not conducing even if the battery is being charged.
2.1.1. When No Battery Charging. Waveforms for this mode are shown in Figure 5(a). In these conditions the converter operates as described next.

(1) During $t_{0} . S_{1}$ is off and $S_{2}$ and $S_{3}$ are on, the equivalent subcircuit is shown in Figure 5(b), and then the inductor $L_{1}$ is being charged with the renewable source; the load is fed only by the output capacitor.

(2) During $t_{1} . S_{1}$ remains off and $S_{3}$ remains on, but $S_{2}$ is turned off, the equivalent subcircuit is shown in Figure 5(c), and then energy stored at the inductor $L_{1}$ is delivered to the output capacitor.

2.1.2. When Battery Charging. Waveforms for this mode are shown in Figure 6(a). In these conditions the converter operates as described next.

(1) During $t_{0} . S_{3}$ is on, but also $S_{1}$ and $S_{3}$ are turned on; the equivalent subcircuit is shown in Figure 6(b), so that inductors $L_{1}$ and $L_{2}$ are charged with the renewable source. Load is only fed from the output capacitor. 


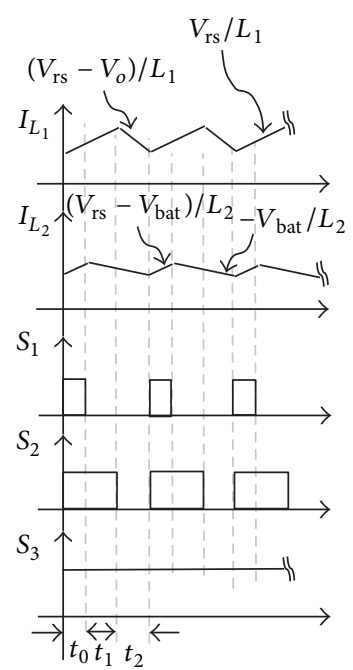

(a) Waveforms

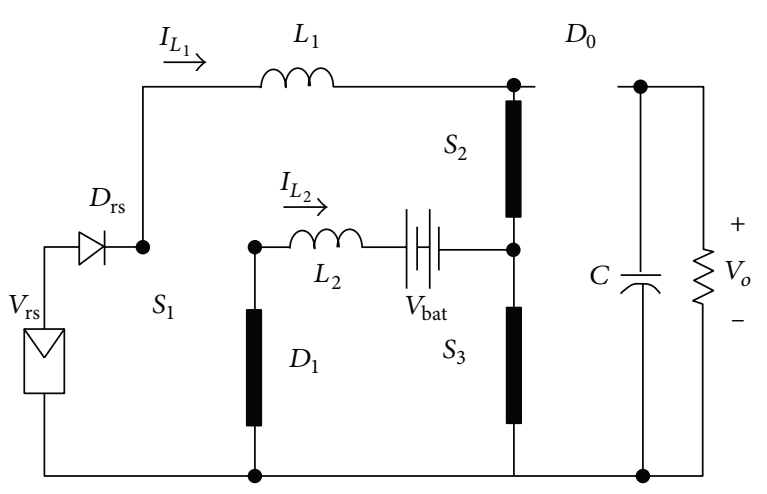

(c) Subcircuit for $t_{1}$

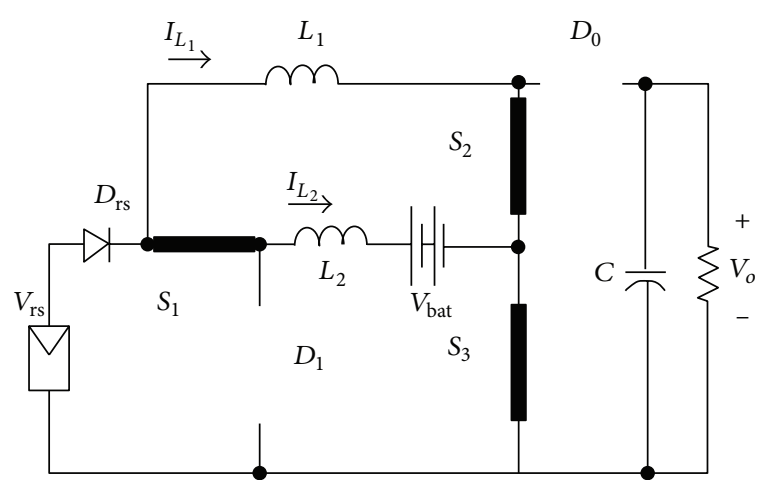

(b) Subcircuit for $t_{0}$

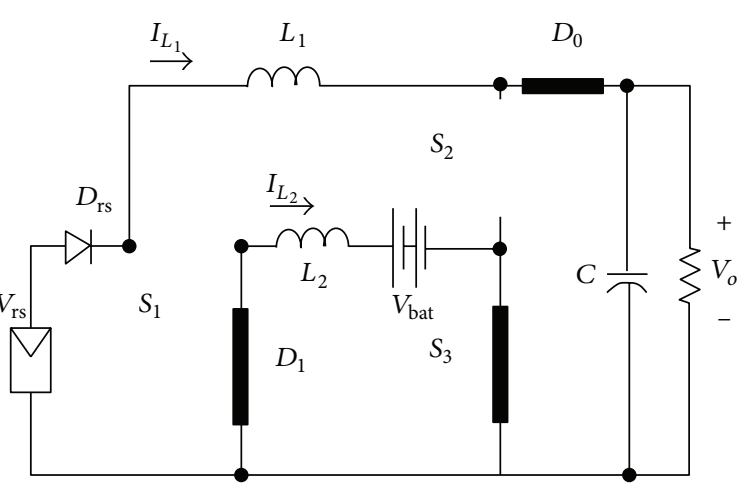

(d) Subcircuit for $t_{2}$

FIGURE 6: Waveforms and subcircuits when the battery set is being charged (mode 1, charging).

(2) During $t_{1} . S_{3}$ remains on and $S_{1}$ may be turned off, but $S_{2}$ is still on; the equivalent subcircuit is shown in Figure $6(\mathrm{c})$, so that inductor $L_{1}$ is still charged, while inductor $L_{2}$ is discharged into the battery set and by the diode $D_{1}$.

(3) During $t_{2} \cdot S_{3}$ remains on, but now $S_{1}$ and $S_{2}$ are off; the equivalent subcircuit is shown in Figure 6(d), so that stored energy at inductors $L_{1}$ and $L_{2}$ is delivered to the output capacitor and the battery set, respectively.

In this mode of operation, the switch $S_{2}$ is always used to control the output voltage. And the switch $S_{1}$ is used to control the charge of the battery set; a MPPT tracker is used for this purpose; except when the renewable energy available is too high, then the current for charging the battery is limited to a maximum value. The energy is taken from the renewable source.

2.2. Mode 2: Delivered Power from the Battery Set. This mode occurs if the photovoltaic panel has no energy (point A in Figure 7) or if the maximum energy which may be obtained from the panel (point B in Figure 7) is lower than the output

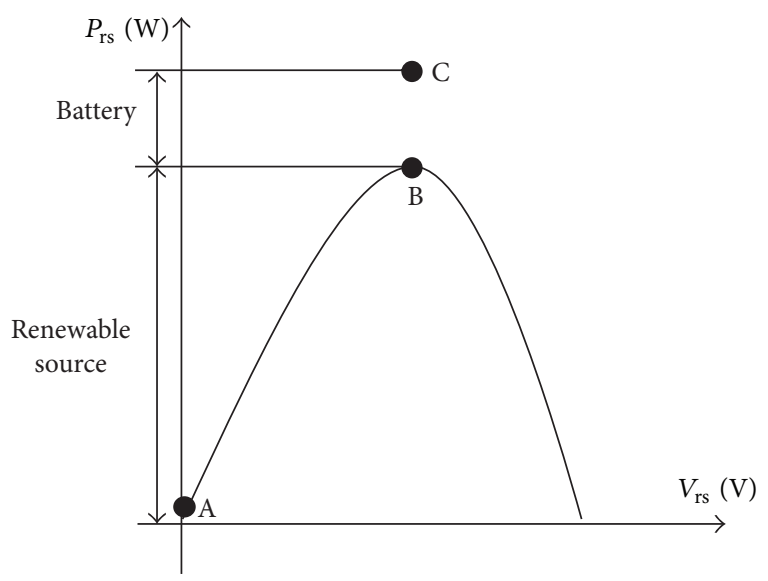

FIGURE 7: Characteristic waveforms of renewable sources and different power outputs.

power (point $\mathrm{C}$ in Figure 7); then it is necessary to use a battery in order to deliver the required amount of energy to the load. 


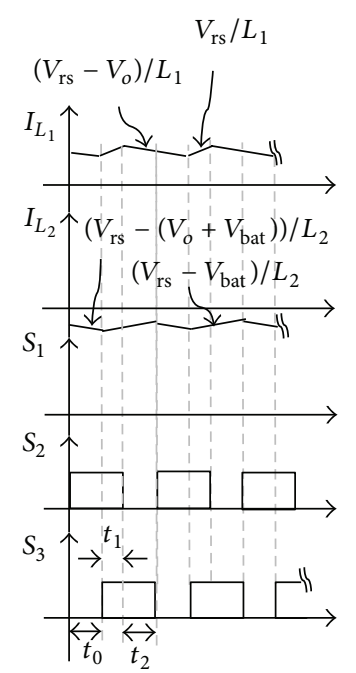

(a) Waveforms

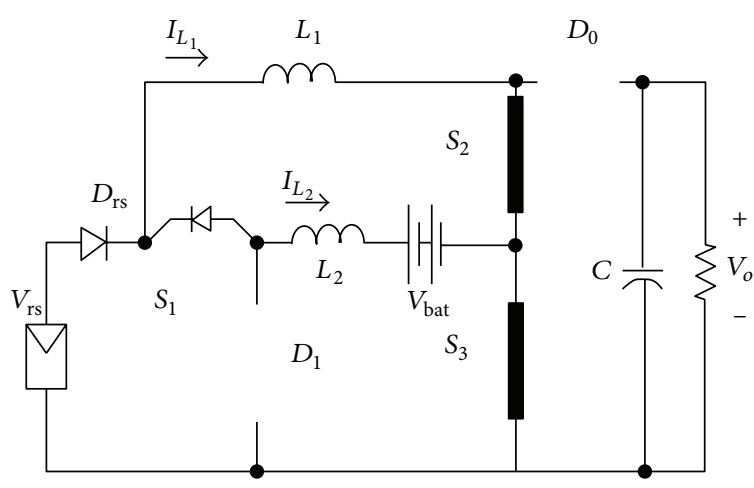

(c) Subcircuit for $t_{1}$

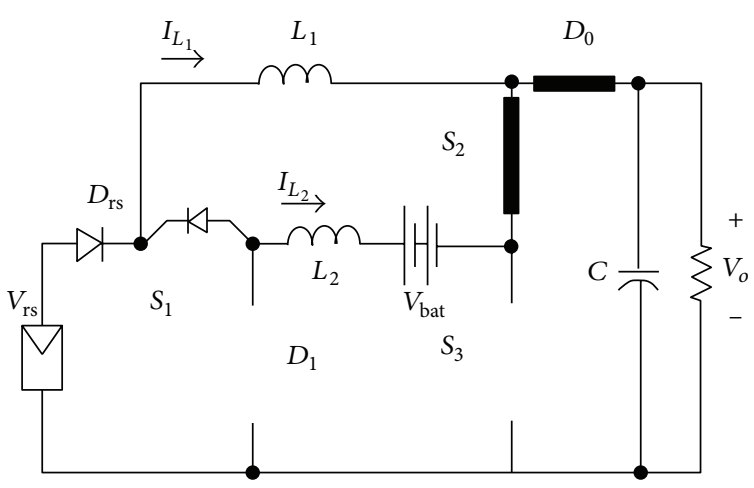

(b) Subcircuit for $t_{0}$

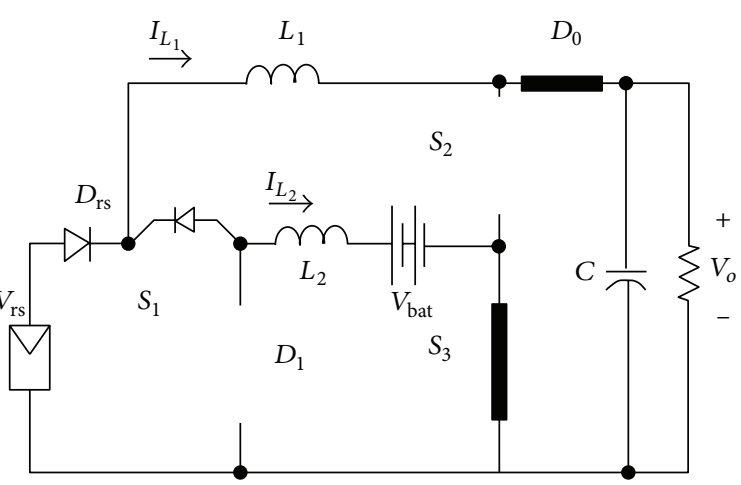

(d) Subcircuit for $t_{2}$

FIGURE 8: Waveforms and subcircuits when the energy is obtained from both sources (mode 2, energy available from renewable source).

By assuming that the converter is operated in mode 1 (switch $S_{3}$ is on), and suddenly the renewable source suffers a power variation that reduces its power capacity for any circumstance, the battery set is automatically connected to the inductor $L_{1}$ through the diode in antiparallel of $S_{1}$, acting as uninterruptible power supply; therefore the power to the load is guaranteed, no matter weather conditions.

The above implies that the operation mode 2 occurs without any change to the switch control signals of mode 1 . However the energy demanded to the renewable source could not be the maximum available from it; therefore the switch $S_{3}$ is used to track the maximum power point during mode 2 .

2.2.1. When Energy Available in Renewable Source. Waveforms for this mode are shown in Figure 8(a). In these conditions the converter operates as described next.

(1) During $t_{0} \cdot S_{1}$ and $S_{3}$ are off, but $S_{2}$ is on; the equivalent subcircuit is shown in Figure 8(b); the inductors $L_{1}$ and $L_{2}$ are discharged.

(2) During $t_{1} \cdot S_{1}$ remains off, but $S_{2}$ and $S_{3}$ are turned on; the equivalent subcircuit is shown in Figure 8(c), and inductors $L_{1}$ and $L_{2}$ are charged from the renewable source. Load is only fed from the output capacitor.

(3) During $t_{2} . S_{1}$ is still off and $S_{3}$ remains on, but $S_{2}$ is turned off; the equivalent subcircuit is shown in Figure 8(d). Stored energy at inductor $L_{1}$ is delivered to the output, while $L_{2}$ is charged.

During all these stages the battery set and the renewable source are delivering energy. It should be noticed that the current in $L_{2}$ is negative because the battery is delivering energy; therefore the diode $D_{1}$, in antiparallel of $S_{1}$, is conducting even if control signal of $S_{1}$ is off.

2.2.2. When Energy Available Only in Battery Set. Waveforms for this mode are shown in Figure 9(a). In these conditions the converter operates as described next.

(1) During $t_{0} . S_{1}$ is off, but $S_{2}$ and $S_{3}$ are on; the equivalent subcircuit is shown in Figure 9(b), so that both inductors $L_{1}$ and $L_{2}$ are charged with energy provided from the battery set. Load is only fed from the output capacitor. 


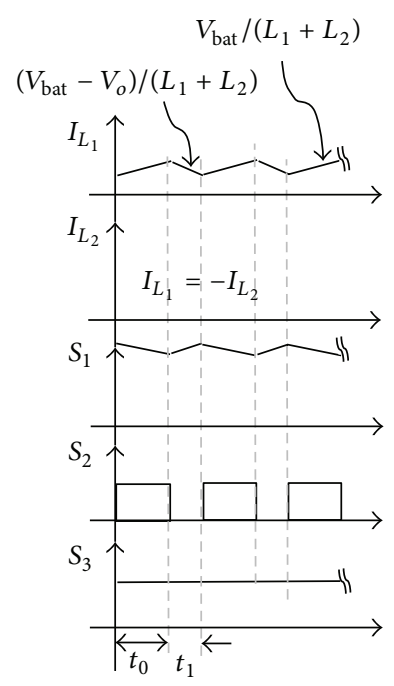

(a) Waveforms

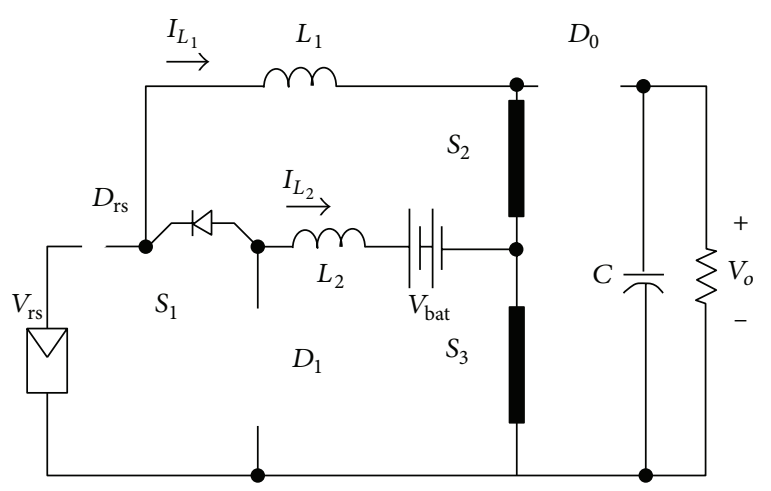

(b) Subcircuit for $t_{0}$

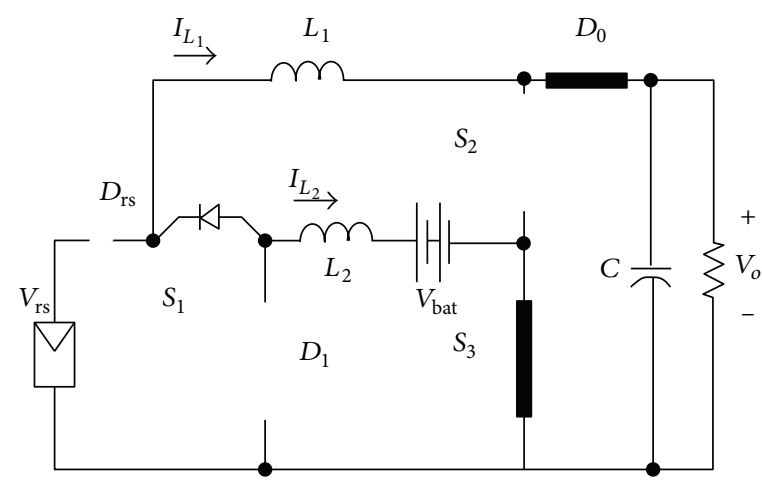

(c) Subcircuit for $t_{1}$

FIGURE 9: Waveforms and subcircuits when energy is supplied from the battery set (mode 2, only battery).

(2) During $t_{1} . S_{1}$ remains off and $S_{3}$ is still on, but $S_{2}$ is turned off; the equivalent subcircuit is shown in Figure 9 (c). Stored energy at inductors $L_{1}$ and $L_{2}$ is delivered to the output capacitor.

Similar to mode 1 , the switch $S_{2}$ is used to control the output voltage; however energy can be taken from the renewable source and the battery set or only just from the battery set. The switch $S_{3}$ is used to track the maximum power point of the photovoltaic panel. If there is no energy in the renewable source, then the battery will deliver all the power to the load.

\subsection{Mode 3: No Power Available. This mode occurs when the} renewable source and the battery cannot supply the energy requirements to the load, because it should not be forgotten that the amount of energy is finite and it depends on the battery set and weather conditions. When this occurs the system is in idle condition, and only the battery set could be charged (once the renewable source is available).

When the renewable source and the battery set do not have enough energy, the output voltage cannot be kept into its acceptable limits of operation. This mode will remain until the battery set is completely charged. To guarantee no energy is delivered to the load a relay is used to disconnect the load.

Table 1 summarizes different switching states which establish the power flow of the system. The switching frequency of the different states is determined by a single carrier; therefore all the switches work under the same frequency when they are operating; the switching period for the system was selected at $20 \mu \mathrm{s}$.

2.4. Analysis of the Converter. Since the converter may be operated in several modes and each one has a different behavior, analysis was made for each specific condition.

In mode 1 switch $S_{3}$ is turned on, but $S_{1}$ and $S_{2}$ are commuting and then only appear at the equations, where the duty cycle is associated with these switches. State variable representation for the system is then as follows:

$$
\begin{gathered}
\frac{d i_{L_{1}}}{d t}=\frac{V_{\mathrm{rs}}}{L_{1}}-\frac{V_{o}}{L_{1}}\left(1-d_{S_{2}}\right) \\
\frac{d i_{L_{2}}}{d t}=\frac{V_{\mathrm{rs}}}{L_{2}} d_{S_{1}}-\frac{V_{\mathrm{bat}}}{L_{2}}
\end{gathered}
$$


TABLE 1: Switching states of the converter.

\begin{tabular}{|c|c|c|c|c|}
\hline \multirow{2}{*}{ Operation mode } & \multicolumn{3}{|c|}{ Switches } & \multirow{2}{*}{ Functions } \\
\hline & $S_{1}$ & $S_{2}$ & $S_{3}$ & \\
\hline \multirow{2}{*}{ Mode 1} & 0 & $\mathrm{X}$ & 1 & Feeding the load with $V_{\mathrm{rs}}$ \\
\hline & $\mathrm{X}$ & $\mathrm{X}$ & 1 & Charging battery and feeding load with $V_{\mathrm{rs}}$ \\
\hline \multirow{2}{*}{ Mode 2} & 0 & $\mathrm{X}$ & $\mathrm{X}$ & Feeding the load from $V_{\mathrm{rs}}$ and $V_{\text {bat }}$ \\
\hline & 0 & $\mathrm{X}$ & 1 or 0 & Feeding the load only with $V_{\text {bat }}$ \\
\hline \multirow{2}{*}{ Mode 3} & $\mathrm{X}$ & 0 & 1 & Charging battery \\
\hline & 0 & 0 & 1 & System off \\
\hline
\end{tabular}

"1" means "on," "0" means "off," and "X" means "commutating."

TABLE 2: Equilibrium point of the operation mode.

\begin{tabular}{lcc}
\hline Operation mode & Equilibrium point & Functions \\
\hline Mode 1 & $V_{o}=\frac{1}{1-d_{S_{2}}} V_{\mathrm{rs}}$ & Feeding the load with $V_{\mathrm{rs}}$ \\
& $V_{\mathrm{bat}}=d_{S_{1}} V_{\mathrm{rs}}$ & Charging battery if required \\
Mode 2 & $V_{o}=\frac{1}{1-d_{S_{2}}-d_{S_{3}}} V_{\mathrm{rs}}$ & Feeding the load from $V_{\mathrm{rs}}$ and $V_{\mathrm{bat}}$ \\
& $V_{\mathrm{bat}}=V_{\mathrm{rs}}-\left(1-d_{S_{3}}\right) V_{o}$ & Feeding the load only with $V_{\mathrm{bat}}$ \\
\hline Mode 3 & $V_{o}=\frac{1}{1-d_{S_{2}}} V_{\mathrm{bat}}$ & Charging battery \\
\hline
\end{tabular}

$$
\frac{d V_{o}}{d t}=\frac{i_{L_{1}}}{C}\left(1-d_{S_{2}}\right)-\frac{V_{o}}{R C},
$$

where $V_{\mathrm{rs}}$ is the renewable voltage source, $V_{\text {bat }}$ is the battery set voltage, $V_{o}$ is the output voltage, $i_{L_{1}}$ is the inductor $L_{1}$ current, $i_{L_{2}}$ is the inductor $L_{2}$ current, $C$ is the output capacitance, $L_{1}$ and $L_{2}$ are the inductances, $d_{S_{1}}$ is the duty cycle of the switch $S_{1}$, and $d_{S_{2}}$ is the duty cycle of the switch $\mathrm{S}_{2}$.

In mode $2 S_{1}$ is turned off, $S_{2}$ is always commuting, and $S_{3}$ may be switching depending on the availability of the renewable source. State variable representation for the system where the renewable source is available is then as follows:

$$
\begin{gathered}
\frac{d i_{L_{1}}}{d t}=\frac{V_{\mathrm{rs}}}{L_{1}}-\frac{V_{o}}{L_{1}}\left(2-\left(d_{S_{2}}+d_{S_{3}}\right)\right) \\
\frac{d i_{L_{2}}}{d t}=\frac{V_{\mathrm{rs}}-V_{\mathrm{bat}}}{L_{2}}-\frac{V_{o}}{L_{2}}\left(1-d_{S_{3}}\right) \\
\frac{d V_{o}}{d t}=\frac{i_{L_{1}}}{C}\left(1-d_{S_{2}} d_{S_{3}}\right) d_{S_{2}}\left(1-d_{S_{3}}\right)-\frac{V_{o}}{R C},
\end{gathered}
$$

Where $d_{S_{3}}$ is the duty cycle of the switch $S_{3}$.
In this mode, when the renewable source cannot provide energy, the valid equations for the system are then as follows:

$$
\begin{gathered}
\frac{d i_{L_{1}}}{d t}=\frac{V_{\text {bat }}}{L_{1}+L_{2}}-\frac{V_{o}}{L_{1}+L_{2}}\left(1-d_{S_{2}}\right) \\
\frac{d i_{L_{2}}}{d t}=-\frac{d i_{L_{1}}}{d t} \\
\frac{d V_{o}}{d t}=\frac{i_{L_{1}}}{C}\left(1-d_{S_{2}}\right)-\frac{V_{o}}{R C} .
\end{gathered}
$$

Particularly for this case $i_{L_{1}}=-i_{L_{2}}$.

Converter in mode 3 operates only in charging mode; therefore the system equations are as follows:

$$
\frac{d i_{L_{2}}}{d t}=\frac{V_{\mathrm{rs}}}{L_{2}} d_{S_{1}}-\frac{V_{\mathrm{bat}}}{L_{2}} .
$$

The equilibrium points of the different operating modes are obtained by making the set of differential equations equal to zero; these are shown in Table 2 . As it is easily seen, the output voltage always depends on the duty cycle of $S_{2}$; hence it is the switch employed to do it.

Particularly for mode 2, when energy is delivered by both sources, switch $S_{3}$, which is related to the battery set, is used for having control of the energy delivered by this source; it should be noticed that $S_{3}$ also affects the output voltage, and in order to maintain a regulated output voltage the $S_{2}$ must be adjusted by the controller.

It should be noted that $S_{1}$ affects only the battery; hence, it is used only when battery requires to be charged. 
TABLE 3: Comparison between converters.

\begin{tabular}{lccc}
\hline Converter & Reported in [8] Figure 2 & Reported in [9] Figure 3 & Proposed scheme \\
\hline Active & & & 3 \\
Diode & 3 & 0 & 3 \\
MOSFET & 3 & 12 & 2 \\
Passive & 1 & 3 & 0 \\
Inductor & 1 & 1 & Good \\
Transformer & Bad & Good & Simple \\
Battery lifetime & Simple & Complex & \\
Operation & & & \\
\hline
\end{tabular}

2.5. Converter Design Issues. The converter was designed to be operated in continuous conduction mode (CCM). Not only inductors were designed based on the desired ripple but also the capacitor.

Inductors $L_{1}, L_{2}$ and the capacitor may be obtained by considering the operation in mode 1 and using the following equations:

$$
\begin{gathered}
L_{1}=\frac{V_{\mathrm{rs}} d_{S_{2}} T_{s}}{\Delta I_{L_{1}}} \\
L_{2}=\frac{\left(V_{\mathrm{rs}}-V_{\mathrm{bat}}\right) d_{S_{1}} T_{s}}{\Delta I_{L_{2}}} \\
C=\frac{V_{o}\left(1-d_{S_{2}}\right) T_{s}}{\Delta V_{C} R},
\end{gathered}
$$

where $T_{S}$ is the switching period, $\Delta I_{L_{1}}$ is the ripple of $L_{1}, \Delta I_{L_{2}}$ is the ripple of $L_{2}$, and $\Delta V_{C}$ is the ripple of $C$.

2.6. Comparison of Proposal with Previous Schemes. Table 3 shows a brief comparison of this proposed converter; it considers the number of semiconductors, the passive elements, the operation of the battery set, and the general form of operation. Schemes appear illustrated in Figure 2 [8] and Figure 3 [9]; both are the most representative in the literature. It is easily observed that converter in this proposal and the one reported in [8] have not only less components than those reported in [9] but also an easier form of operation. Although this proposal has similar features than those offered in [8], it is not the same with the battery use; this proposal will only employ the battery when it is required to do so; however, the other scheme will use it during all the operating modes, which diminish its lifetime.

The other two schemes consider isolation, which may be a disadvantage in this proposal since it is not taken into account; however, if more components are added it may become suitable.

\section{Controlling the Converter}

There are three switches, and each one is used for one purpose, as mentioned before in Section 2.4. Output voltage for this converter is controlled using a traditional controller,

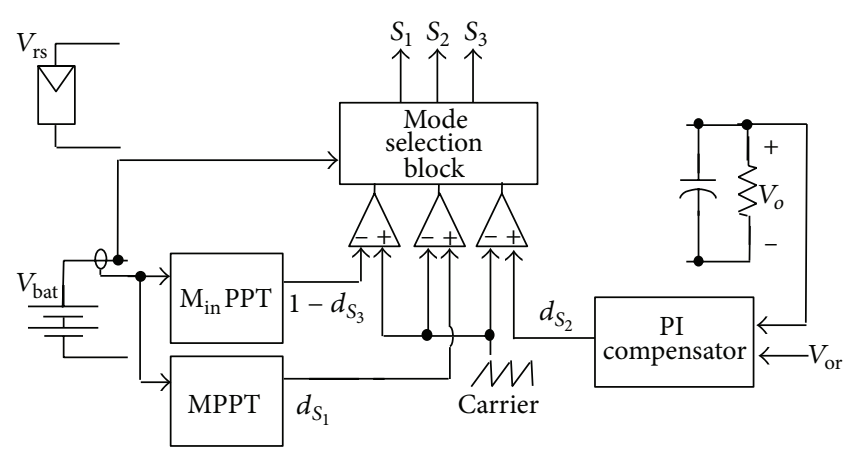

FIGURE 10: Block diagram of the controller.

but an integrator must be in it; the employed switch for this purpose is $S_{2}$. This switch controls the output voltage independently if the converter is operated in mode 1 or 2 , even from where the energy is taken; which permits to operate easily the system. It is important to notice that even if the renewable source is suddenly not available, the system operates properly, because in a natural way the energy is taken from the battery set due to the diode $D_{\mathrm{rs}}$ and the antiparallel diode of $S_{1}$.

For controlling the charge of battery, switch $S_{1}$ is used, and this occurs in modes 1 and 3.

Particularly when operating in mode 2 , when switches $S_{2}$ and $S_{3}$ are commuting, $S_{3}$ establishes the amount of energy taken from each input source; it comes either from the renewable source or from the battery set. A maximum power point tracker (MPPT) algorithm is used in order to optimize the use of the renewable source; although a traditional maximum power point tracker is reported in the literature, a minimum power point tracker $\left(\mathrm{M}_{\mathrm{in}} \mathrm{PPT}\right)$ focused on the battery is suggested in this paper and is only necessary to sense the battery.

In Figure 10 the controller employed is shown; as it may be observed the voltage compensator (PI), the $\mathrm{M}_{\text {in }} \mathrm{PPT}$ tracker, the battery charger (MPPT), the pulse width modulation (PWM) section, and the mode selection block are used. Battery voltage is considered to determine if the battery requires to be charged or not, while the battery current is used to switch between modes and enable the control signal of each semiconductor. 
3.1. Voltage Regulator. A traditional controller, which is a PI compensator, is used in order to regulate the output voltage. The output capacitor voltage and reference are introduced into the compensator in order to obtain the duty cycle, and then $d_{S_{2}}$ is considered in a typical PWM controller based on a carrier signal, which determines the switching frequency, as shown in Figure 10. The switch used is $S_{2}$.

The equation considered is then as follows:

$$
u_{S_{2}}=k_{p} e_{o}+k_{i} \int e_{o} d t=0
$$

where $e_{o}$ is the output voltage error $\left(e_{o}=V_{o}-V_{\text {or }}\right)$ and $V_{\text {or }}$ is the voltage reference.

It should be noticed for this controller that, although perturbations may occur, the integral part reduces the steady state error. Actually, output voltage depends on both switches in mode 2, as seen in Table 2, and for reducing the coupling issue, the compensator includes an integral term.

3.2. $M_{\text {in }}$ PPT Algorithm. Maximum power point of the renewable source is obtained by centering the algorithm on the battery set, and then instead of a MPPT a different method is used to obtain the maximum energy from the renewable source. This algorithm is used when the battery set provides energy to the load and there is still energy from the renewable source (mode 2).

The system is focused on obtaining the minimum power from the battery set in order to make sure that the maximum power is delivered from the renewable source, where this condition is achieved easily. Therefore a minimum power point tracker $\left(\mathrm{M}_{\mathrm{in}} \mathrm{PPT}\right)$ for the battery set is considered; the battery power is not required, since the battery set voltage is almost constant, and then only the current of the battery set may be used.

Flowchart of the proposed $\mathrm{M}_{\text {in }}$ PPT algorithm is shown in Figure 11. Since current is the only variable, which is measured, the proposed technique becomes simpler than other methods. Once it is detected that the battery set is in use and delivering energy to the load, the algorithm is performed; then the duty cycle of $S_{3}$ is changed. At the beginning the duty cycle is equal to one and then decreases until the minimum power is obtained; the system remains oscillating at the $\mathrm{M}_{\text {in }} \mathrm{PP}$ until the current of the battery set is zero; this means that the renewable source is able to deliver all the energy to the load and the battery set is not required.

After obtaining the duty cycle, it is introduced into a PWM; it should be noticed that the comparator inputs are changed and the compliment of the $d_{S_{2}}$ is used in order to obtain the signals as the proposed operation in mode 2 .

3.3. Charging the Battery. A voltage-current mode method, which is similar to methods in uninterruptible power supplies (UPS), was implemented for charging the battery set. Voltage is employed to determine when the battery set either is fully charged or requires to be charged; the current is used to control the battery set charging.

This stage may occur in mode 1 or 3 . As the energy is taken from the renewable source, a maximum power point

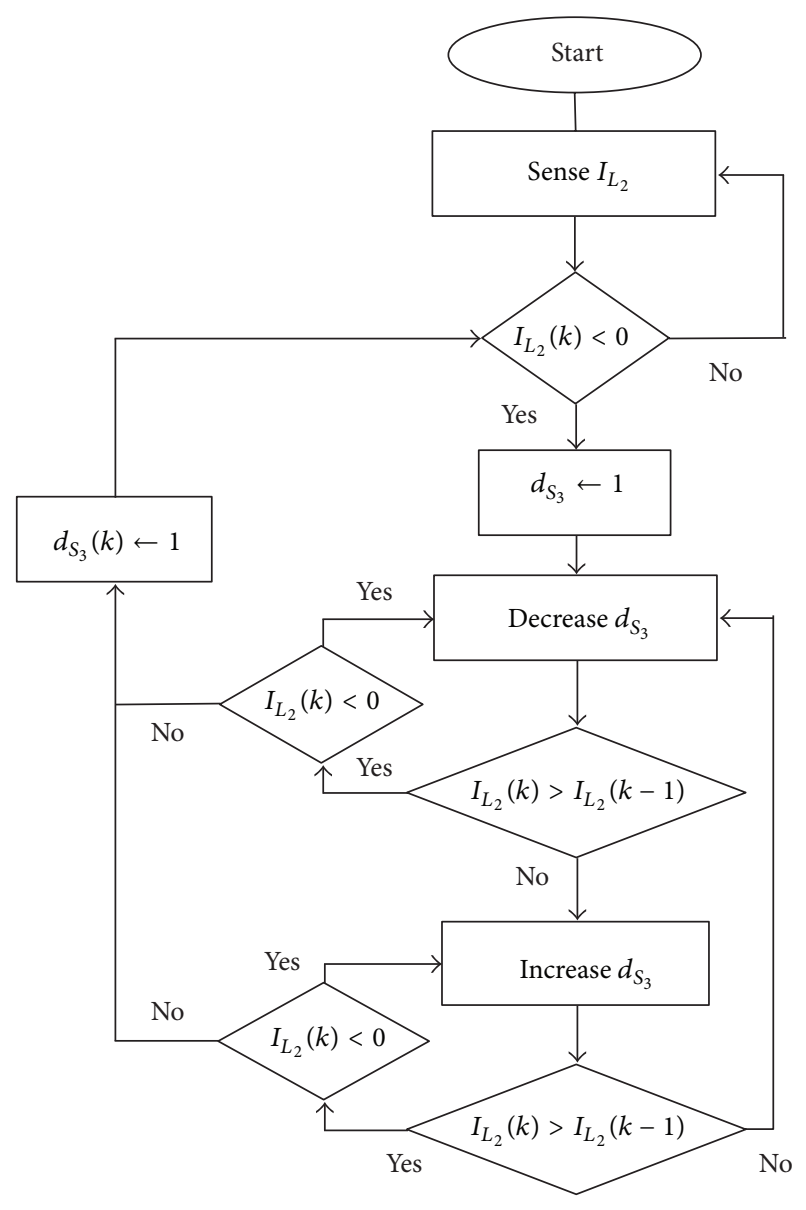

FIGURE 11: Flowchart of the tracking algorithm.

is considered. It is assumed that the battery set voltage is constant, and then only the current is required in the algorithm, similar to that implemented in the previous section; but here the traditional maximum power tracker is used.

Additionally to the MPPT, the battery current is bounded to a maximum value, which allows avoiding the increase of the power to the battery that may cause damage in it.

3.4. Mode Selection Block. For establishing the mode of operation, a mode selection block is considered; it enables the respective control signal of each mode, and this is made depending on conditions for the system. Basically the battery voltage and current are used.

\section{Experimental Results}

System functionality was experimentally evaluated with a built prototype, so that the proposed idea was validated. The battery set is of $24 \mathrm{~V}$, the renewable source is a photovoltaic solar panel emulator of Agilent (6131), the output voltage is $100 \mathrm{~V}$, and the converter was designed for an output power of $100 \mathrm{~W}$; the switching frequency is $50 \mathrm{KHz}, L_{1}$ and $L_{2}$ are $700 \mu \mathrm{H}$, and $C_{o}$ is $100 \mu \mathrm{F}$. 


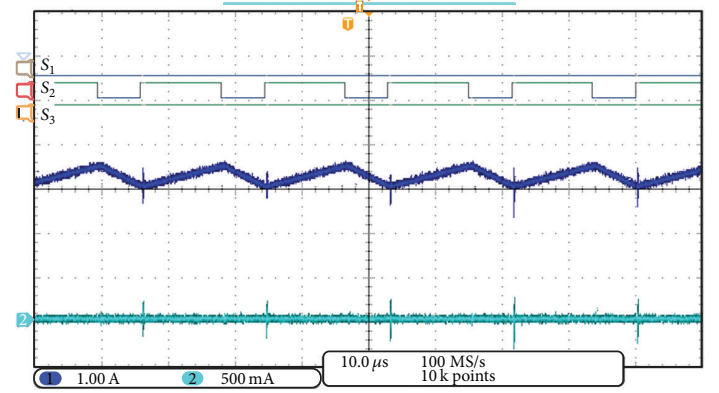

FIGURE 12: Operation when the energy is obtained from the renewable source. From top to bottom: $S_{1}, S_{2}, S_{3}, I_{L_{1}}$, and $I_{L_{2}}$. The current reference of both inductors is the same.

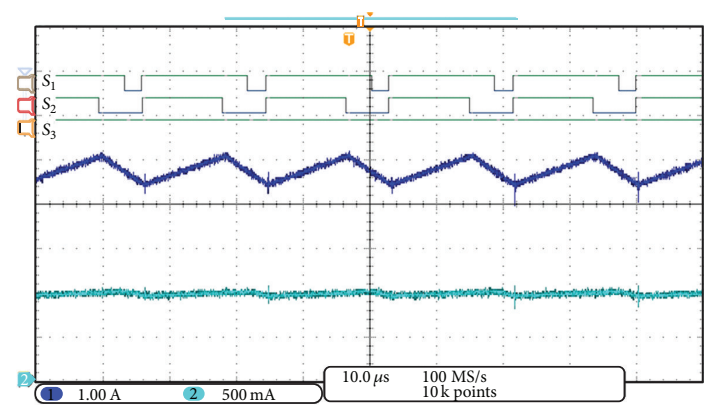

FIGURE 13: Operation when the battery set is being charged from top to bottom: $S_{1}, S_{2}, S_{3}, I_{L_{1}}$, and $I_{L_{2}}$. The current reference of both inductors is the same.

The experimental prototype was tested under different operating conditions. First, the performance of the converter in the different modes in steady state is addressed; second, the performance under power variation of the renewable source is addressed; third, some tests were applied to the system under transitions due to the battery set conditions; and finally a test under load variations is made.

4.1. Steady State Operation. Figures 12 through 15 show experimental results for different operation modes; they were obtained with a mixed signals oscilloscope. For illustration purpose, results were not graphed at the designed conditions, which allow comparing with the theoretical waveforms; this is explained because the ripple values cannot be well appreciated at the full output power and designed conditions. Then the output power in this case is $20 \mathrm{~W}$.

Figure 12 shows operation in mode 1 , when the renewable source is available, but no charging is required. For this case the available energy from the photovoltaic panel is higher that the load power, so that no battery needs to be used. As it is easily seen only inductor $L_{1}$ provides energy to the load; since inductor $L_{2}$ has no current the battery is not in use. The efficiency in this condition is around $93 \%$.

Figure 13 shows system operation in mode 1, when the battery set is charged from the renewable source. For this case it is considered that required energy to the renewable source is able to satisfy the load necessities; it is clearly seen how both inductors have current; $L_{1}$ provides energy to the load and $L_{2}$

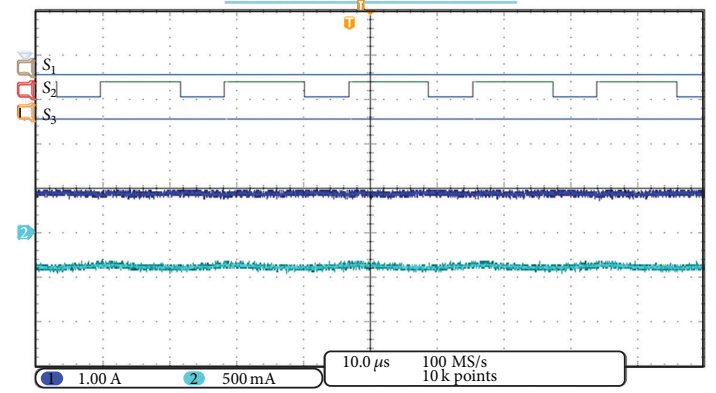

FIGURE 14: Operation when the energy is obtained from the battery set from top to bottom: $S_{1}, S_{2}, S_{3}, I_{L_{1}}$, and $I_{L_{2}}$. The current reference of both inductors is the same.

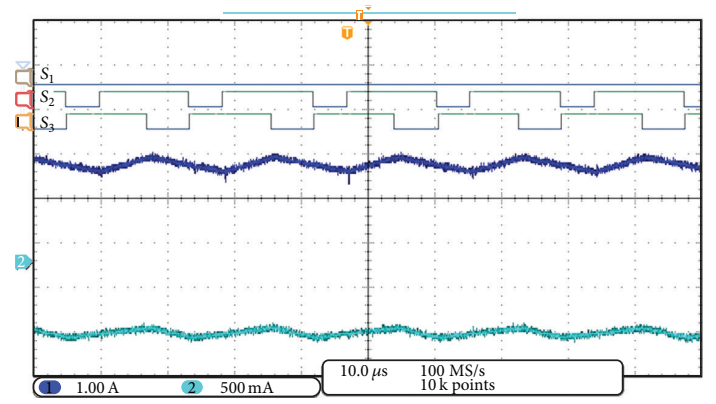

Figure 15: Operation when the energy is obtained from the battery set and the renewable source from top to bottom: $S_{1}, S_{2}, S_{3}, I_{L_{1}}$, and $I_{L_{2}}$. The current reference of both inductors is the same.

provides to the battery set. The efficiency in this condition is around $93 \%$.

Figure 14 shows operation in mode 2, when the available energy from the renewable source is null; then all the energy is obtained from the battery set. It is seen how both inductors, $L_{1}$ and $L_{2}$, have the same current in magnitude, but opposite sign; for this case the battery is discharged through both inductors. The efficiency in this condition was around $89 \%$.

Figure 15 shows operation in mode 2; when the available energy from the photovoltaic panel is less than that required by the output, then the battery set is used as a compliment; it is easily seen how both sources deliver energy to the load and how current in both inductors is different; however they are delivering energy to the load. The efficiency in this condition was around $91 \%$.

It is important to notice that the efficiency depends on the devices in use and also the operating conditions; this should be improved if other devices are considered. Different inputs and/or outputs were considered because the battery port is bidirectional; the efficiency was calculated as

$$
\eta=\frac{\sum_{n} P_{\text {on }}}{\sum_{m} P_{\text {im }}}
$$

where $P_{\text {on }}$ is the " $n$ "th output power and $P_{\text {im }}$ is the " $m$ "th input power.

4.2. Renewable Power Source Variation. The proposed system was tested under a renewable source variation in order to 


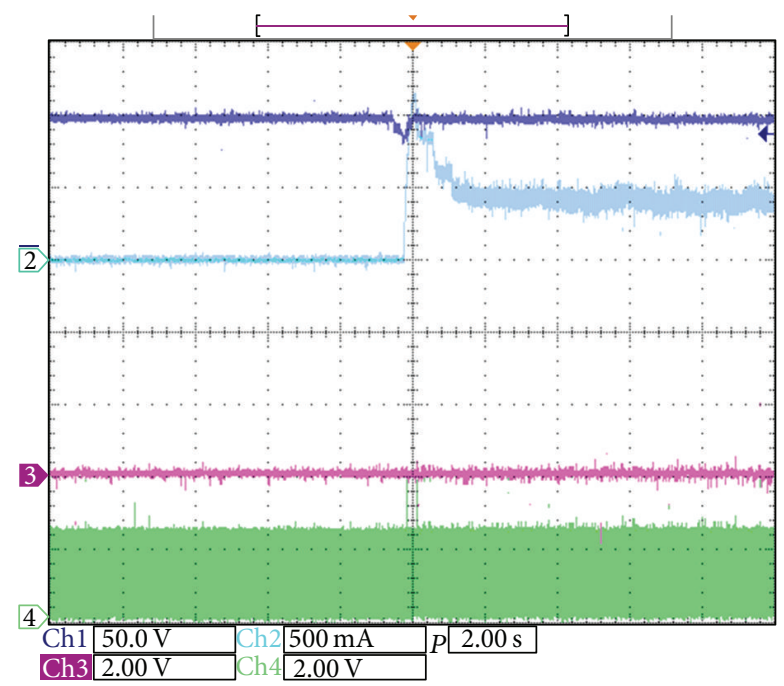

FIGURE 16: Operation when suddenly the maximum power energy of the renewable source becomes lower than the output power from top to bottom $V_{o},-I_{L_{2}}, S_{2}$, and $S_{1}$.

carry consistently validation. Henceforth the proposed power point tracker algorithm was tested.

Figure 16 shows the system operation when the renewable source suffers a variation. The initial MPP of the renewable source is $V_{\mathrm{mpp}}=48 \mathrm{~V}$ and $I_{\mathrm{mpp}}=2.5 \mathrm{~A}\left(V_{\mathrm{oc}}=60 \mathrm{~V}, I_{\mathrm{sc}}=\right.$ $3 \mathrm{~A}$ ), which means a higher output power than the initially considered in the test $\left(P_{o}=100 \mathrm{~W}\right)$; then suddenly the MPP is changed to $V_{\text {mpp }}=35 \mathrm{~V}$ and $I_{\text {mpp }}=2.5 \mathrm{~A}\left(V_{\text {oc }}=43 \mathrm{~V}, I_{\mathrm{sc}}=\right.$ $3 \mathrm{~A}$ ); this represents a lower power demanded by the load. It should be noticed that the system automatically demands part of the energy to the battery (see current of inductor $L_{2}$ ); the system is properly maintained in operation.

It is important to notice that after the transition the MPP of the renewable source is not assured, but then $\mathrm{M}_{\text {in }}$ PPT starts to operate. As it is seen in the figure, the current of the battery set is changed until the minimum battery current is obtained by reaching the MPP of the renewable source; this was made by changing the duty cycle of the switch $S_{3}$.

Figure 17 shows the system operation when the renewable source returns to the initial condition; then the energy available from the renewable source is enough to satisfy the load requirements. As it may be noticed, after the transition the battery does not deliver energy.

4.3. Operation under Different Battery Set Conditions. To verify the system operation some tests were made under variation of battery set conditions, when charging starts and when stop is considered and when charging starts and when stop is considered.

Figure 18 shows the operation of the systems when the battery set is being charged. The MPP of the renewable source is $V_{\mathrm{mpp}}=48 \mathrm{~V}$ and $I_{\mathrm{mpp}}=2.5 \mathrm{~A}\left(V_{\mathrm{oc}}=60 \mathrm{~V}, I_{\mathrm{sc}}=\right.$ $3 \mathrm{~A})$, this means that initial power is higher than the output power considered in the test $\left(P_{o}=100 \mathrm{~W}\right)$; the battery is required to be charged, and then the system starts to charge

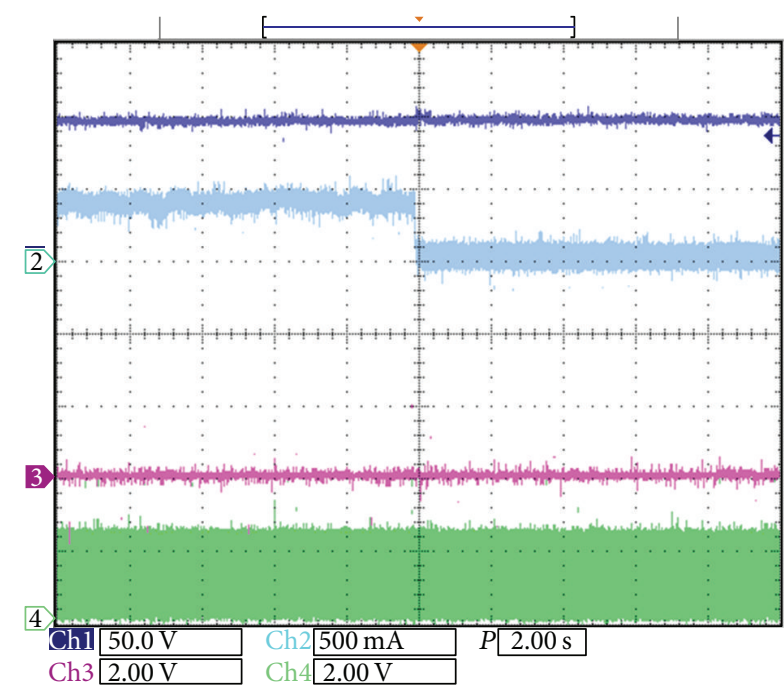

FIGURE 17: Operation when suddenly the maximum power energy of the renewable source becomes higher than the output power from top to bottom: $V_{o},-I_{L_{2}}, S_{2}$, and $S_{1}$.

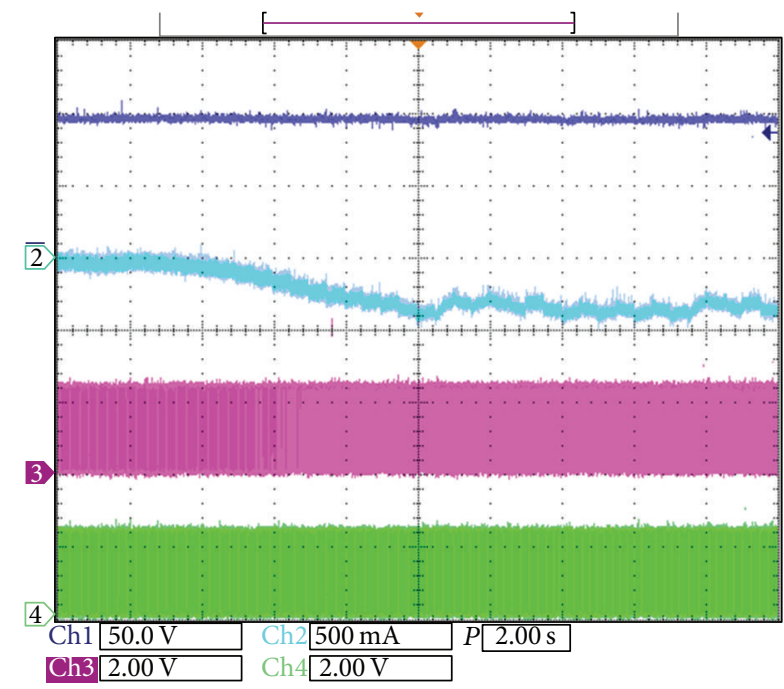

FIGURE 18: Operation when battery set charging starts from top to bottom: $V_{o},-I_{L_{2}}, S_{2}$, and $S_{1}$.

it, but demanding the maximum power available from the renewable source.

Figure 19 shows the operation of the systems when the battery set is stopped to be charged. The MPP of the renewable source is $V_{\mathrm{mpp}}=48 \mathrm{~V}$ and $I_{\mathrm{mpp}}=2.5 \mathrm{~A}\left(V_{\mathrm{oc}}=\right.$ $\left.60 \mathrm{~V}, I_{\mathrm{sc}}=3 \mathrm{~A}\right)$; this means that initial power is higher than the output power considered in the test $\left(P_{o}=100 \mathrm{~W}\right)$; the battery initially is being charged, and when it is detected to be fully charged, then the charging is stopped.

4.4. Load Variation. A load variation was made in order to complete the tests. Figure 20 shows the performance of the system when the load is changed from $50 \%$ to $100 \%$ of the power; the system was operated under mode 1 . The triggering 


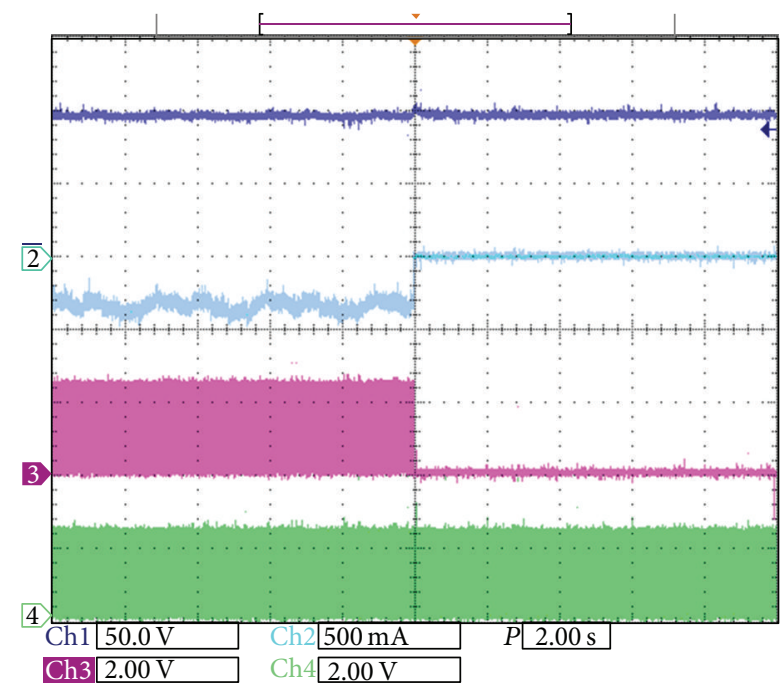

FIGURE 19: Operation when battery set charging stops from top to bottom: $V_{o},-I_{L_{2}}, S_{2}$, and $S_{1}$.

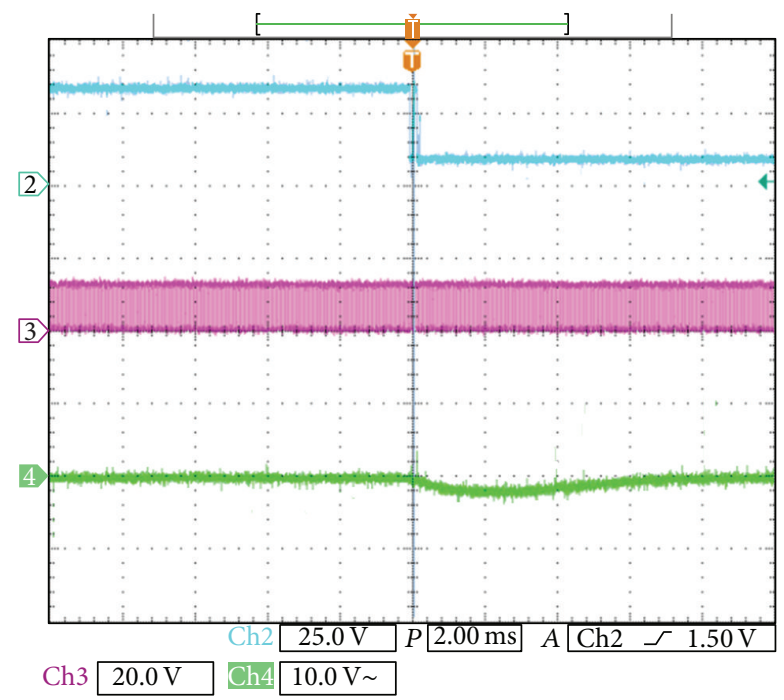

Figure 20: Operation under a load variation from top to bottom: triggering signal, $S_{2}$, and $V_{o}$ (AC mode).

signal of the event, the control signal of $S_{2}$, and the output voltage put in AC mode are also illustrated. As it is seen, the system operates in a satisfactory manner, the settling time is around $5 \mathrm{~ms}$, and the undervoltage is around $2 \mathrm{~V}$.

\section{Conclusion}

Three-port DC/DC converter in renewable applications should be able to handle both the renewable source and the battery set; this is because the energy from these sources depends on their availability, and especially for the battery set its utility period of life should be taken into account.

A different three-port DC/DC converter is suggested in this paper, one port for the renewable source, the second for the battery set, and finally the output port. Power may be demanded from both input voltages simultaneously or each one independently. The battery set may also be charged from the renewable source. This proposal has the feature that battery port is used only when it is required; this offers an increase of lifetime. Also when the renewable source suddenly is not available the system automatically takes energy from the battery set without any change, only after an MPPT is used to optimize the use of the renewable source.

The operation and analysis of the converter were given. Experimental results were also shown.

\section{Conflict of Interests}

The authors declare that there is no conflict of interests regarding the publication of this paper.

\section{References}

[1] Y.-M. Chen, Y.-C. Liu, and F.-Y. Wu, "Multi-input DC/DC converter based on the multiwinding transformer for renewable energy applications," IEEE Transactions on Industry Applications, vol. 38, no. 4, pp. 1096-1104, 2002.

[2] Y.-M. Chen, Y.-C. Liu, and S.-H. Lin, "Double-input PWM DC/DC converter for high-/low-voltage sources," IEEE Transactions on Industrial Electronics, vol. 53, no. 5, pp. 1538-1545, 2006.

[3] B. G. Dobbs and P. L. Chapman, "A multiple-input DC-DC converter topology," IEEE Power Electronics Letters, vol. 1, no. 1, pp. 6-9, 2003.

[4] Y.-M. Chen, Y.-C. Liu, S.-C. Hung, and C.-S. Cheng, "Multiinput inverter for grid-connected hybrid PV/wind power system," IEEE Transactions on Power Electronics, vol. 22, no. 3, pp. 1070-1077, 2007.

[5] N. Vázquez, A. Hernández, C. Hernández, E. Rodríguez, R. Orozco, and J. Arau, "A double input DC/DC converter for photovoltaic/wind Systems," in Proceedings of the IEEE Power Electronics Specialists Conference (PESC '08), pp. 2460-2464, Rodes, Greece, 2008.

[6] C. L. Shen and S. H. Yang, "Multi-input converter with MPPT feature for wind-PV power generation system," International Journal of Photoenergy, vol. 2013, Article ID 129254, 13 pages, 2013.

[7] V. M. Pacheco, L. C. Freitas, J. B. Vieira Jr., E. A. A. Coelho, and V. J. Farias, "A DC-DC converter adequate for alternative supply system applications," in Proceedings of the 17th Annual IEEE Applied Power Electronics Conference and Expositions, pp. 1074-1080, Dallas, Tex, USA, March 2002.

[8] H. Al-Atrash, F. Tian, and I. Batarseh, "Tri-modal half-bridge converter topology for three-port interface," IEEE Transactions on Power Electronics, vol. 22, no. 1, pp. 341-345, 2007.

[9] J. L. Duarte, M. Hendrix, and M. G. Simões, “Three-port bidirectional converter for hybrid fuel cell systems," IEEE Transactions on Power Electronics, vol. 22, no. 2, pp. 480-487, 2007.

[10] H. Tao, J. L. Duarte, and M. A. M. Hendrix, "Three-port triplehalf-bridge bidirectional converter with zero-voltage switching," IEEE Transactions on Power Electronics, vol. 23, no. 2, pp. 782-792, 2008. 
[11] H. Krishnaswami and N. Mohan, "Three-port series-resonant DC-DC converter to interface renewable energy sources with bidirectional load and energy storage ports," IEEE Transactions on Power Electronics, vol. 24, no. 10, pp. 2289-2297, 2009.

[12] Z. Qian, O. Abdel-Rahman, H. Al-Atrash, and I. Batarseh, "Modeling and control of three-port DC/DC converter interface for satellite applications," IEEE Transactions on Power Electronics, vol. 25, no. 3, pp. 637-649, 2010. 

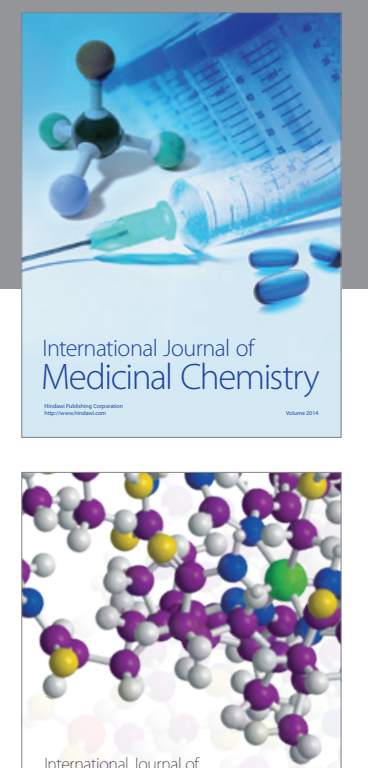

\section{Carbohydrate} Chemistry

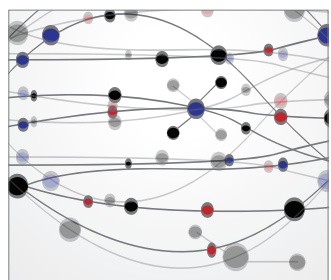

The Scientific World Journal
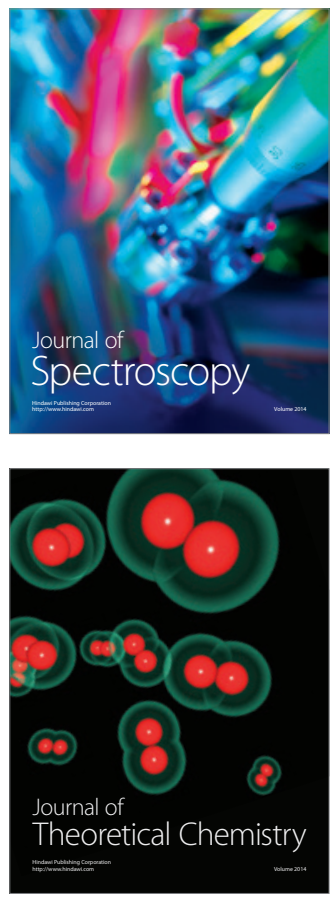
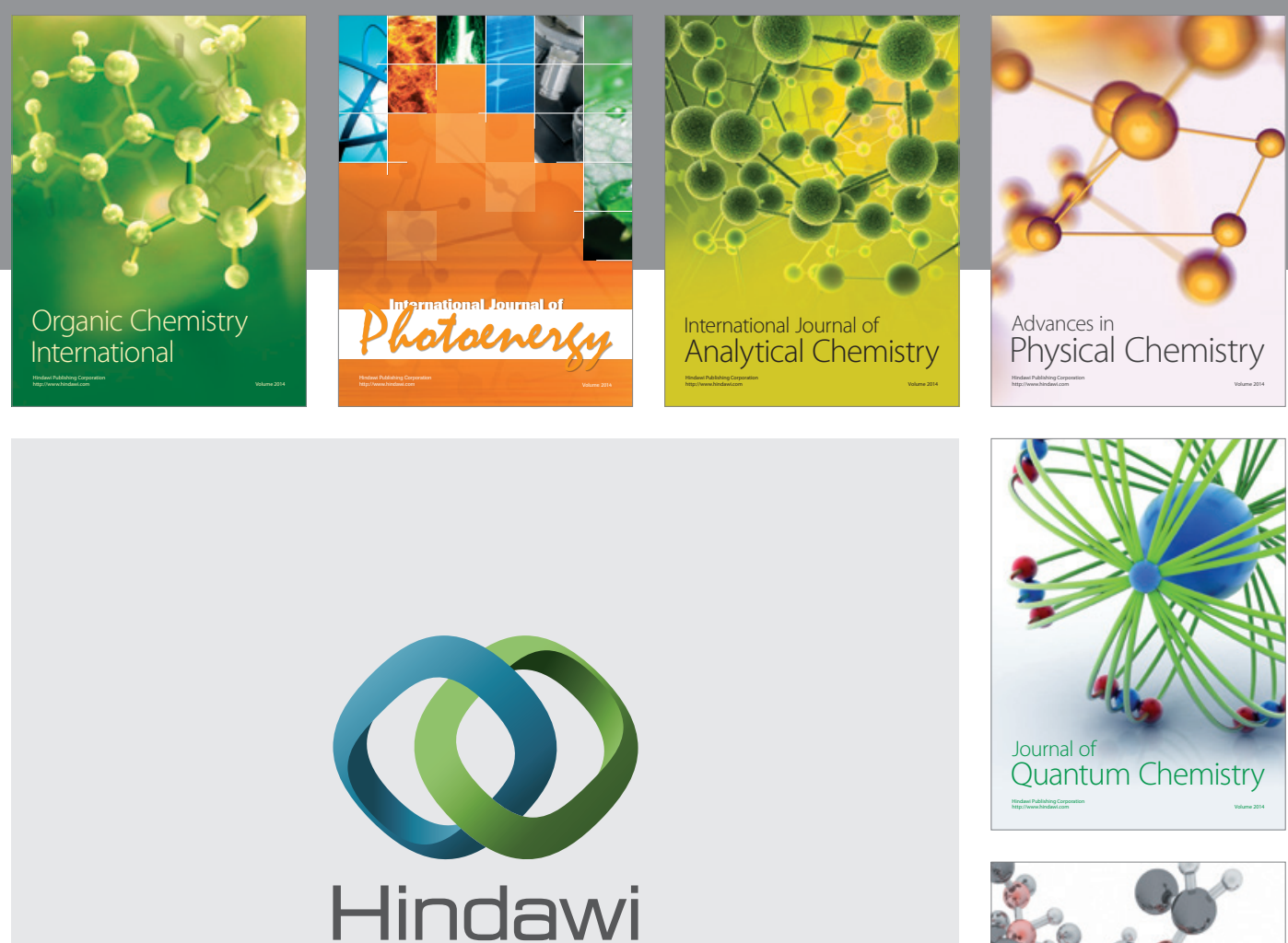

Submit your manuscripts at

http://www.hindawi.com

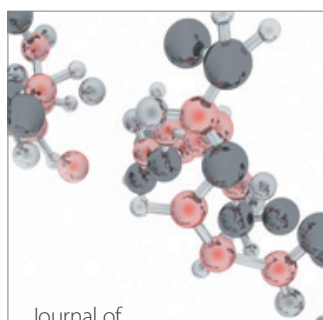

Analytical Methods

in Chemistry

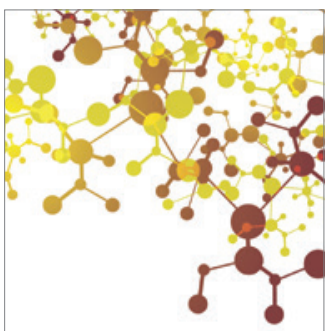

Journal of

Applied Chemistry

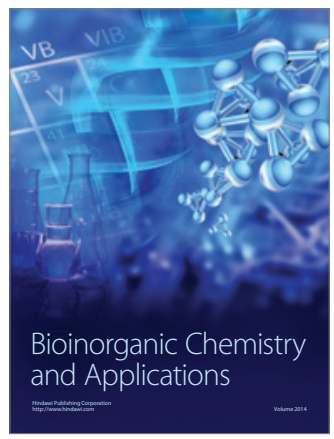

Inorganic Chemistry
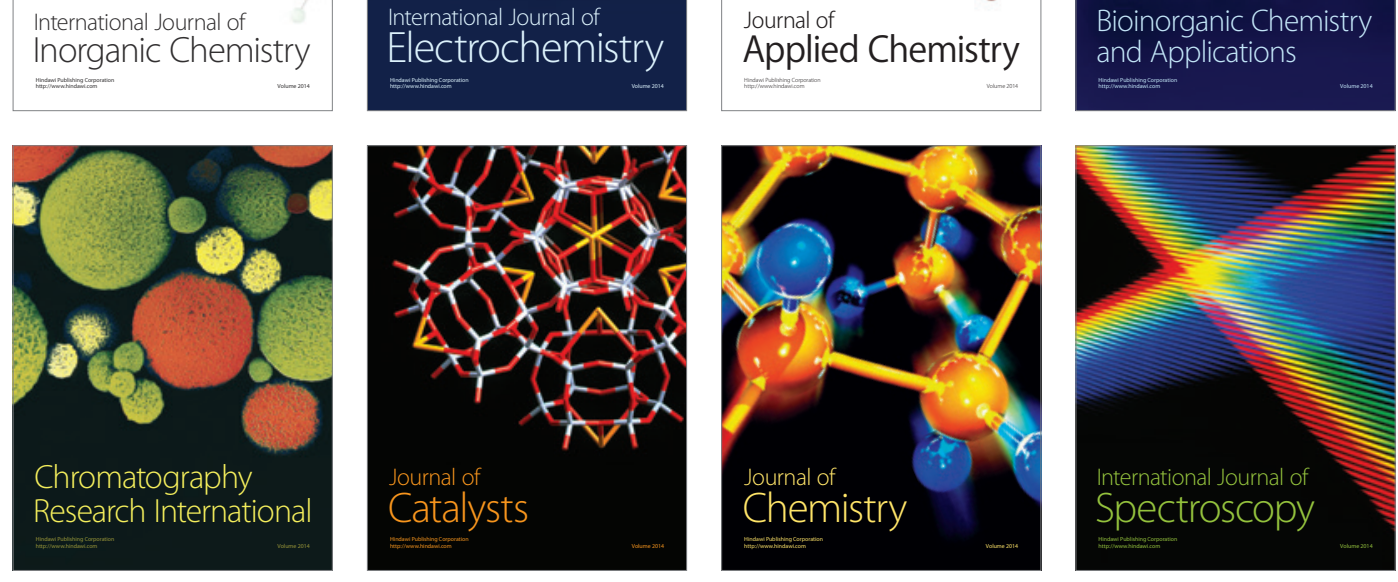